\title{
The experiences of caregivers providing home care for terminally ill family members at the end of life: A phenomenological study in Bahrain
}

\author{
Fatima Saleh*, Catherine S. O'Neill \\ Ministry of Health, Bahrain
}

Received: October 23, 2017

Accepted: February 7, 2018

Online Published: April 2, 2018

DOI: $10.5430 /$ cns.v6n3p57

URL: https://doi.org/10.5430/cns.v6n3p57

\begin{abstract}
Objective: The aim of the study was to explore the lived experience of caregivers providing home care for terminally ill family members, with the objectives of describing their experiences of caring for relatives who are terminally ill with cancer and the needs of home caregiving in Bahrain.

Methods: The study adopted a Heideggerian, hermeneutic phenomenological design, with a purposive sample of eight family caregivers. Data was generated through one to one, in-depth interviews and analyzed using Interpretative Phenomenological Analysis.

Results: Three main themes emerged from the data: (1) the burden of care, (2) comforts, and (3) coping. The findings showed that the lived experience of home caregiving includes physical, emotional and financial burdens, combined with a lack of professional support. The collective experience was infused with intense emotions because of a lack of structured support, resulting in negative emotions that frequently affected the caregivers' well-being and their ability to care for the ill person. Nevertheless, caregivers tried to maintain care and comforts for their terminally ill relative in the home. They adopted the home environment, arranged resources to ease caring and provided psychological care. Caregivers utilized three coping mechanisms, faith, personal strategies and distribution of the care responsibilities among family members.

Conclusions: Caregivers were not prepared for the commitment and burdens of home care when a family member is terminally ill. A recommendation from the study findings is that training be offered on nursing care before patients discharge. In addition, a reactivation of the palliative care clinic hotline service would support family caregivers. A further recommendation is that home nursing care and hospice services be established to improve homecare services for family caregivers in Bahrain.
\end{abstract}

Key Words: Family, Terminal cancer, End-of-life, Palliative home care, Caregiver needs

\section{INTRODUCTION}

In the Kingdom of Bahrain, 5,966 Bahraini were diagnosed with cancer in the period from January 1998 to December 2011, 426 cases on annual average. ${ }^{[1]}$ Breast cancer was the most prevalent cancer in females while in males it was lung cancer. ${ }^{[2]}$ Cancer is the fourth cause of death in Bahrain. ${ }^{[3]}$ The Ministry of Health (MOH) Bahrain has adopted a strat- egy of shorter hospital stays which places most of the patient care responsibility on families. Additionally, one of the priorities identified by $\mathrm{MOH}$ is to investigate the burden disease places on families and society. ${ }^{[4]}$ In a palliative care philosophy the family is considered the unit of care. ${ }^{[5]}$ People who are terminally ill require complex care. Frequently this is the responsibility of family members as the ill persons

*Correspondence: Fatima Saleh; Email: alahwathy@gmail.com; Address: Ministry of Health, Bahrain. 
are too sick to manage their own care and are dependent on family caregivers. ${ }^{[6]}$ The literature attests to the numerous challenges experienced by caregivers delivering home care. ${ }^{[6-15]}$ Providing care for terminal cancer patients at home causes immense physical and mental exhaustion to the caregivers. ${ }^{[14,15]}$ As a consequence, family caregivers develop physical and psychological illnesses during caregiving. ${ }^{[6,7,14-16]}$ In addition, they report unmet needs. ${ }^{[16-19]}$

\section{Background}

Systematic reviews of qualitative and quantitative literature concerning relatives requirements caring for family members at the end of life care, Funk et al. ${ }^{[11]}$ and Stajduhar et al. ${ }^{[13]}$ documented that relatives have complex needs different from the people they are caring for, and should be treated as individuals with unique needs. ${ }^{[17-19]}$ Frequently caregivers experience giving care as a burden because of the responsibilities involved in helping the patient survive the journey of cancer, or alternatively to have a peaceful death. ${ }^{[6,7,20]}$ In addition, carers frequently engage in home care for a sick relative while simultaneously working outside the home full time. Ultimately, the burden of care disrupts the caregivers personal needs and social relationships. Furthermore, caregiving may cause feelings of frustration and guilt if the caregiver fails to fully meet the patient's needs. ${ }^{[15]}$

According to Hudson and Payne ${ }^{[10]}$ research studies in home based palliative care need to be carried out in order to ascertain how much support and assistance is given by health institutions to support family caregivers. It is imperative for nurses to assess the needs of the patient's family prior to discharge to ensure effective care provision at home that will alleviate patient as well as family suffering. ${ }^{[5,16]} \mathrm{In}$ terestingly, international studies reported unmet needs despite the availability of home nursing care and hospice services. ${ }^{[15-19,21]}$ Through professional interactions with the family members caring for terminal cancer relatives, the first author became aware of the difficulties relatives experienced in providing home care for terminally ill relatives. Moreover, currently there is no home care hospice services available to the Bahraini population. This was the impetus for the current study.

\section{RESEARCH DESIGN}

A qualitative research design and in particular a Heidegger hermeneutic phenomenology was adopted. A purposive sample of eight caregivers was used to generate data. Data analysis adopted the framework of Interpretative Phenomenological Analysis (IPA) of Smith et al. ${ }^{[22]}$

Participants had to be the primary caregiver of a cancer patient who was diagnosed as terminally ill and who was attend- ing the oncology outpatient clinic or who had being admitted as an in-patient. In addition, the caregiver needed to be an adult, over the age of 18 years, and was willing to participate in the research and had given written informed consent.

Ethical review and access was obtained from the university's Research Ethics Committee (REC) and from the hospital's REC. Participants were accessed in the oncology outpatient clinic through the palliative care nurse as they accompanied patients' to regular clinic appointments. Some caregivers declined to participate for various reasons. For example, some could not give the time for the research interview, while another female caregiver refused to participate because of the audio recording; hence only two participants were recruited through the oncology outpatient clinic. Ultimately participants were recruited by the first author from the oncology wards and one private/general ward. At the time of the study, the first author was a senior staff nurse in the health institution; however, she was not known to most of the caregivers, and was not involved in their care, thus, caregivers did not feel obliged to participate in the study. Nevertheless, she was directly involved in the care of two participants from the sample as the patients were admitted in the private/general ward where she worked.

The first author provided participants with an information sheet that explained the purpose of the research. Following this they were requested to sign an informed consent form giving their permission to participate in the research. The informed consent contained detailed information about the participants' rights of anonymity, confidentiality, privacy, the right to withdraw besides the safety and storage of data following the guidelines in Schneider et al. ${ }^{[23]}$ Participants' names were not used; instead a code number was assigned for every participant. The consent form clarified that the interview would be audio recorded and that the participants had the right to ask for the recording to be returned to them or be destroyed and not to be used, provided this request was made within 4 weeks of the interview. It was noted in the consent form that on completion of the study, audio files would be destroyed in compliance with the $\mathrm{MoH}$ regulations. Recordings were stored in a password protected computer file for data analysis. The consent and information sheet had been translated into Arabic.

Data were collected through one to one, in depth interviews. An interview topic guide was constructed prior conducting the in depth interviews as suggested by Smith et al. ${ }^{[22]}$ The topic guide consisted of fourteen topics with additional prompt and probe questions as recommended by Smith et al. ${ }^{[22]}$ The questions aimed at capturing the lived caring experience of caring at home. The topic guide was reviewed by the second author who helped in modifying the questions. 
The order of the questions was also a consideration. The questions that would incite emotions were revised in order to avoid provoking participants' feelings, especially at the beginning of the interview. A decision was taken to move these toward the middle and end of the schedule (see Table 1) where they hopefully were not experienced by participants as upsetting. All interviews were conducted in Arabic.

Table 1. Interview guide ${ }^{[24-27]}$

\begin{tabular}{ll}
\hline Code of participant: & Age: \\
Gender: & Marital Status:
\end{tabular}

Contact Number:

1. Could you tell what is it like to be the caregiver of a patient with terminal cancer?

2. Describe the best day in the caregiving experience at home.

3. Describe the worst day in the caregiving experience at home.

4. How do you manage to cope with caregiving on a day-to-day basis, how do you deal with it?

Prompt: Do you have particular strategies for helping you? Ways of coping, practical, mental.

5. What are the family needs to care for patient at home?

6. Who provide those needs?

7. What do you find helpful in the care giving experience? Have you used outside resources and services for help and information?

8. What do you find unhelpful in the care giving experience? Have you felt you needed more help or information on any area so far?

9. What is the impact of caregiving experience on your?

-Mental status

-Health

-Life

-Relationships

-Social life

-Work

-Financial status

10. Does the experience bring you closer to the patient or does it distance you more?

Prompt: Can you tell me more about that?

11. What one word will best describe how you felt about the patient diagnosis of terminal cancer?

12. How do you do you feel caring for your relative knowing that he/she may not recover?

13. Do you feel that you have gained a lot through caring for your relative?

Probe: Explain.

14. Is there anything you can tell me that would be helpful to other people in a similar situation and that may help them?

The first question was broad and general: "Could you tell what is it like to be the caregiver of a patient with terminal cancer?" Usually carers described the feelings associated with caring in response to this question. When the carer did not fully describe the story of the home caring experience, the researcher asked: "Describe a full day, what do you do for the patient from morning till night?" The answer always produced a narrative that illuminated the phenomena under investigation. Generally, participants responded freely and openly to the questions that were used to elicit their experiences of caring. The use of prompt and probing

techniques for example: "Can you tell me more about that?" and probes like: "What happened after that? were focused on uncovering the caregivers' needs and their struggles." The researcher designed the questions following a review of the literature ${ }^{[24-27]}$ and also based on her professional expertise in this area. Following the pilot interview and a review of the data generated by both authors the interview schedule was slightly modified, especially in relation to the sequencing of the questions. The questions that may have incited emotions were modified with the help of the supervisor to avoid causing undue emotional distress, and they were moved towards 
the end of the schedule. For example, Q11: "What one word will best describe how you felt about the patient diagnosis of terminal cancer?" and Q12: "How do you feel caring for your relative knowing that she/he may not recover?" Prior to asking these questions, the researcher alerted the participants that they may find the coming question difficult; this strategy worked well to neutralize any shock a participant may experience if the questions were asked without preparation. Understandably, all participants found it difficult to answer both questions without expressing sadness. Three female participants cried and the interview was adjourned. Support was given and the participants were asked if they wanted to stop the interview process but they decided to continue. The researcher sensed the pain and sorrow of one male participant by the tone of his voice. Despite all the sadness participants were able to proceed with the interviews. The last question was changed following the pilot interview to: "What do you wish to happen to the oncology health services in the future?" The researcher used pilot interview to help her in assessing the quality of the constructed questions. The researcher found the questions reliable and valid as they generated data that answered the research question.

The first author interviewed the primary caregivers of terminal cancer patients; the interview was conducted in a private room to maintain privacy. The primary carers were interviewed alone away from the patients to allow them to freely articulate their experiences. In one instance, the primary caregiver was interviewed in the presence of the patient, because the caregiver was also a patient, who had been admitted with advanced cancer. In this particular case both were caring of each other simultaneously. The interviews generally lasted between 52-113 minutes. All were audio recorded using a voice digital recorder. Additionally, the first author used memos to record important body language during the interview. ${ }^{[23]}$ Some participants reported feeling relieved as a result of interviewing.

\subsection{Participants}

According to Eatough and Smith ${ }^{[24]}$ and Smith et al., ${ }^{[22]}$ IPA studies are usually conducted using small number of participants because the exhaustive analysis of every transcript takes long period with the aim of producing detailed explanation of the lived experiences. Thus, IPA is described as an idiographic form of examination, striving for a careful analysis of cases more than aiming for generalizations. IPA sacrifices breadth for depth by its commitment to a detailed interpretive account of case by case analysis. This may logically be achieved using very small number of participants. In fact, Smith is recently advocating the detailed examination of a single case study. ${ }^{[22,24]}$
In all eight family caregivers were recruited between the oncology outpatients clinic, the oncology wards, and a private/general ward. The average age of the primary caregivers was 43 years. Five were females, with three males, all caring for relatives who were terminally ill with cancer. Participants familial relationships were sisters (2), daughters (2), a brother, son, father, and a wife. The patients were diagnosed with Breast, Ovarian, Brain, Lung, Bladder, and Thyroid cancer. All had metastasis. More details about participants length of care and ability of patients are presented in (see Table 2). Data saturation was reached when interviews generated repeated information.

\subsection{Data analysis}

IPA was used to analyze the data (see Table 3). IPA was developed as a distinctive analysis approach for qualitative research in psychology. ${ }^{[28]}$ It is intertwined with the theoretical underpinnings of phenomenology and hermeneutics, which is the methodology of this research. Based on Heidegger's hermeneutically philosophy, the relationship between individuals and their world is hermeneutic deduced as a hermeneutic circle. ${ }^{[24]}$ Hence, IPA is a two stage interpretation method that helps the researcher make sense of participants making sense of their experiences; this is called double hermeneutic. ${ }^{\text {[29] }}$

\subsection{IPA}

IPA is informed by three key concepts, Phenomenology, Hermeneutics and Idiography. ${ }^{[22]}$ Thus, in presenting and discussing the findings the analyst is guided by the hermeneutic circle that moves from the part (individual case) to the whole (group level) and idiography focuses on the particular to uncover the phenomenon of interest. Therefore, the reader will witness the appearance of shared experiences with occasional light shed on what is unique in the individual stories. Table 2 provides an idiographic representation of the caregivers' unique stories in keeping with IPA concept of ideography. ${ }^{[22]}$

The first author translated the interviews into English. She transcribed the interviews verbatim in order to immerse herself in the participants' experiences which helped to fulfill step one of IPA analysis which is reading and re-reading. The translation and transcribing process was lengthy and involved an investment of time. "Express Scribe Software" helped somewhat to speed up the transcription process. It took the first author a month to translate and transcribe all the interviews, a process which assisted her in being confident that she had truly immersed herself in the data and which oriented her to the participants' life world in the initial interpretation of data. 
Table 2. Idiographic representation of caregivers' stories

\begin{tabular}{|c|c|c|c|}
\hline $\begin{array}{l}\text { Participant } \\
\text { Information }\end{array}$ & $\begin{array}{l}\text { Patient's } \\
\text { Diagnosis/Age/Gender }\end{array}$ & Length of Care \& Ability of patient & What is unique about their stories... \\
\hline $\begin{array}{l}\text { 1. Sister } \\
48 \text { yrs/Female/ } \\
\text { Not working }\end{array}$ & $\begin{array}{l}54 \text { yrs/Female: } \\
\text { Two primary cancers, Breast } \\
\text { and Ovarian CA with liver \& } \\
\text { abdomen lymph nodes } \\
\text { metastasis on palliative } \\
\text { chemotherapy since } 2002\end{array}$ & $\begin{array}{l}\text { Walking patient, she can eat \& go to } \\
\text { toilet, however, when in pain ADL } \\
\text { become very limited. Caregiving } \\
\text { duration is } 10 \text { years. }\end{array}$ & $\begin{array}{l}\text { The Family of Cancer Story: } \\
\text { Three sisters had cancer in this family. The caregiver is also advanced cancer patient. } \\
\text { She forgot her sickness; she refuses to leave her sister. When interviewed, she was } \\
\text { schedules for surgery and chemotherapy and delayed her treatment because her sister } \\
\text { was sick, receiving chemo. for pain control. The doctor insisted that she must start her } \\
\text { treatment as he was afraid she may deteriorate. } \\
\text { "I hate the hospital because I have to come every day. Today morning when I came I } \\
\text { was hiding my tears from her. I feel finish I am fully overloaded." }\end{array}$ \\
\hline $\begin{array}{l}\text { 2. Wife } \\
30 \mathrm{yrs} / \text { Female/ } \\
\text { House Wife }\end{array}$ & $\begin{array}{l}\text { Brain Tumor, Glioblastoma } \\
\text { grade } 4 \text { with progressive } \\
\text { disease, MRSA/42 yrs/Male }\end{array}$ & $\begin{array}{l}\text { Dependant, he had difficulty walking, } \\
\text { urinary incontinence, difficulty } \\
\text { concentrating. Patient used to be wet all } \\
\text { the time needing bathing \& changing. } \\
\text { Caregiving duration is one year. }\end{array}$ & $\begin{array}{l}\text { "A huge big burden" Story: } \\
\text { This case is estimated as the most difficult caring experience. The patient was } \\
\text { dependant "he had difficulty walking" so the participant kept on repeating: "I suffered } \\
\text { a lot with carrying and helping him to set." The patient had urinary incontinence so she } \\
\text { spends her day in the bathroom as the patient gets wet all the time, hence frequent } \\
\text { bathing and changing. To add more pressure, patients brothers were controlling in } \\
\text { nature, they did not allow her to arrange resources to ease caring. There was no help } \\
\text { given to her and she could not even take break. }\end{array}$ \\
\hline $\begin{array}{l}\text { 3. Daughter } \\
42 \text { yrs/Female/ } \\
\text { House Wife }\end{array}$ & $\begin{array}{l}\text { CA Lung with liver } \\
\text { metastasis for supportive care } \\
\text { with SOB and poor feeding/ } \\
77 \text { yrs/Male }\end{array}$ & $\begin{array}{l}\text { One month, first hospital admission in } \\
\text { patient's life. Bedridden, blind, needs } \\
\text { to be carried to bathroom for bath. } \\
\text { Caregiving duration is one month. }\end{array}$ & $\begin{array}{l}\text { The Cooperative Family Story: } \\
\text { All the family shared in the caregiving experience. Patient had many carers. Sons, } \\
\text { daughters, brothers and sisters in law and their children. All cooperated to collect } \\
\text { money, buy things for home caring. The patient prefers home so the family took him } \\
\text { home although it was risky but as the carer said: } \\
\text { "People say keep your father in the hospital it is more comfortable for you; I said it is } \\
\text { more comfortable for us but my father is not comfortable since my father is not } \\
\text { comfortable we also are not comfortable." }\end{array}$ \\
\hline $\begin{array}{l}\text { 4. Sister } \\
54 \text { yrs/Female/ } \\
\text { Retired }\end{array}$ & $\begin{array}{l}\text { Breast CA with metastasis of } \\
\text { mediastinal lymph nodes. } \\
\text { Presently } 3 \text { rd time } \\
\text { recurrence, scheduled for } \\
\text { chemotherapy \& mastectomy } \\
\text { since } 2000 / 48 \text { yrs/Female }\end{array}$ & $\begin{array}{l}12 \text { years, patient can do most ADL on } \\
\text { her own. When tired or stressed, she } \\
\text { needs assistance. }\end{array}$ & $\begin{array}{l}\text { Suffering with pain and worry: } \\
\text { The caregiver had tumor in } 2000 \text { but she kept quite because her sister at that year was } \\
\text { diagnosed with cancer and was under treatment. She kept quiet until her sister finished } \\
\text { treatment. She spoke about her cancer only when it became advance. When diagnosed } \\
\text { she was stage } 4 \text {. Although suffering with severe pain, she is caring for her sister. She } \\
\text { said: } \\
\text { "I forgot myself. I wish their sickness for me not for them." } \\
\text { The patient does not allow the caregiver to give her care so they always quarrel. }\end{array}$ \\
\hline $\begin{array}{l}\text { 5. Brother } \\
56 \text { yrs/Male }\end{array}$ & $\begin{array}{l}\text { CA Bladder for supportive } \\
\text { care/72 yrs/Male }\end{array}$ & $\begin{array}{l}21 \text { years, he was walking though during } \\
\text { the whole period, only required } \\
\text { companion to doctors' visits, since one } \\
\text { year \& four months the patient became } \\
\text { bedridden. }\end{array}$ & $\begin{array}{l}\text { The story of caregiver who could not cope: } \\
\text { The patient is bedridden, had no children. His wife is also advanced cancer patient and } \\
\text { bedridden as well. The family took the patient home, arranged all resources for care, } \\
\text { however they had no one to give on-going care so the next day they brought patient } \\
\text { back to the hospital. That's mean they give home care for one day only. The patient had } \\
\text { no children; additionally his wife was also suffering from advanced cancer and also } \\
\text { bedridden: } \\
\text { "We do not have anybody to care for him. He make dirt on himself, he needs caring and } \\
\text { we do not have anyone to care for him and his wife is also sick, laying on bed, she is } \\
\text { already been cared for. She needs a nurse, both of them need." }\end{array}$ \\
\hline $\begin{array}{l}\text { 6. Son } \\
28 \text { yrs/Male/ } \\
\text { Journalist }\end{array}$ & $\begin{array}{l}\text { CA Breast with multiple } \\
\text { metastasis, Rt. shoulder } \\
\text { pain/54 yrs/Female }\end{array}$ & $\begin{array}{l}6 \text { years, she had difficulty carrying } \\
\text { heavy things, c/o body pain, reduced } \\
\text { activity, but she remained active. }\end{array}$ & $\begin{array}{l}\text { The carer faced many challenges with the healthcare system. The palliative care } \\
\text { service was stopped. The doctor was not available, a new Dr was assigned who was not } \\
\text { approachable and overloaded: } \\
\text { "It was a big problem for me, that the Dr could not answer because the Dr was changed } \\
\text { and the new one was not available, it was difficult to see him and when you come for } \\
\text { him he says million patient. No one solved this problem for me if she develops a } \\
\text { breathing problem how could I solve it? There was no answer and I used to live in } \\
\text { anxiety because of this problem only how can I face it at home?" }\end{array}$ \\
\hline $\begin{array}{l}\text { 7. Father } \\
62 \mathrm{yrs} / \mathrm{Male} / \\
\text { Retired }\end{array}$ & $\begin{array}{l}\text { Medulloblastoma, grade } 4 . \\
\text { Brain Tumor underwent } \\
\text { craniotomy in } 2009\end{array}$ & $\begin{array}{l}4 \text { years, weak balance in walking, after } \\
\text { operation he needed assistance to move } \\
\text { him from place to another. }\end{array}$ & $\begin{array}{l}\text { The recovered patient: } \\
\text { The carer was coping well his main problem was fear that cancer returns: } \\
\text { "Yes I am afraid God willing it won't come back. I feel anxious sometimes but this is } \\
\text { in God's hand." }\end{array}$ \\
\hline $\begin{array}{l}\text { 8. Daughter } \\
28 \text { yrs/Female/ } \\
\text { College } \\
\text { student }\end{array}$ & $\begin{array}{l}\text { NHL, metastatic papillary } \\
\text { CA thyroid, poor feeding, } \\
\text { reduced activity DM, HTN. } \\
72 \text { yrs/Male }\end{array}$ & $\begin{array}{l}\text { One year, bed ridden, needs assistance } \\
\text { with mobilization, bath, offering urinal, } \\
\text { wound dressing for bed sores, offering } \\
\text { food, water, medicines, he does not eat } \\
\text { anything, he drink milk only. }\end{array}$ & $\begin{array}{l}\text { This carer cares for her father (patient), mother who is diabetic, and takes care of home } \\
\text { matters. "My eating reduced a lot. I lost a little weight. I started to forget a lot in a } \\
\text { strange way. I forget a lot everything. Many times we were about to get fire at home } \\
\text { because I cook and forget the cooked, I get distracted by home duties and I forget. I get } \\
\text { headache because of not sleeping when I sleep it relieves." }\end{array}$ \\
\hline
\end{tabular}

MAXQDA computer software was utilized to speed up the process of analysis as it supports IPA according to its devel- author to open all interviews transcripts simultaneously, conAll interviews were stored in one place, allowing the first opers. MAXQDA helped to manage the data more efficiently. sequently facilitating movement between interviews. This 
helped in simplifying the process of searching for connections across emergent themes (step four of IPA) and in looking for patterns across cases (step six of IPA). In addition, this gave the first author the opportunity to grasp a holistic sense of all the interviews, a process that subsequently helped in walking the hermeneutic circle gradually moving from the part to the whole. Concept mapping focused on the research aims helped to reduce the themes to four themes. Concepts maps facilitated the searching for connections across emergent themes (step four of IPA) besides looking for patterns across cases (step six of IPA). Writing and rewriting the findings draft with concept mapping, in addition to the help from the second author, themes were reduced further to three main themes. To ensure rigor and trustworthiness, Lucy Yardley (2000) criteria for assessing the quality of IPA research was followed as recommended by Smith et al. ${ }^{[22]}$ It has four broad principles: 1) sensitivity to context, 2) commitment and rigor, 3) transparency and coherence, 4) impact and importance. Sensitivity to context was shown by constructing an interview guide that focused on discovering the experience of home care at the end of life and most of the questions were taken from the reviewed literature. ${ }^{[24-27]}$ One participant added to the actual sample was interviewed for pilot study to test the validity and reliability of the research questions used in the interview. The interview guide was discussed with the researcher's supervisor who helped in modifying the questions that addressed participants' feelings about knowing the diagnosis and the subject of death. This sensitivity proved to be correct during interviewing as participants found these the most difficult to respond to during the interviews. A few participants cried around the last questions, in this case the interview was stopped and support provided.

Furthermore, the author used probe and prompt techniques during interviewing to encourage participants to fully ex- press their experiences. Transparency is about describing clearly the stages of the research process, a decision trail and research journal were used to explain the process of decision making. Enlisting the assistance of experienced researcher is called "Peer Debriefing" a strategy recommended to maintain rigor in qualitative research. ${ }^{[30]}$ Table 2 presents detail description of each participant story for clarity. The coherence was maintained during the write up; several drafts were written and were critiqued by the supervisor before the final draft. The academic supervisor helped in ensuring that the written text presented the data findings. In addition, the first author used the consolidated criteria for reporting qualitative research (COREQ $)^{[31]}$ checklist as a guide in reporting this study. According to Tong et al., ${ }^{[31]}$ the (COREQ) checklist may help researchers to produce detailed and comprehensive qualitative reports. The significance of the research is that it is the first study of its kind in Bahrain addressing the lived experience of family caregivers at the EOL and Bahraini culture. It is hoped that the findings will be utilized to improve the supportive services for terminal oncology patients and their families in the home.

Table 3. IPA Framework ${ }^{[22]}$

\begin{tabular}{|ll|}
\hline Step one & Reading and re-reading \\
Step two & Initial noting \\
Step three & Developing emergent themes \\
Step four & Searching for connections across emergent themes \\
Step five & Moving to the next case \\
Step six & Looking for patterns across cases \\
\hline
\end{tabular}

\section{RESUltS}

Three main themes emerged from the data analysis: (1) the burden of care, (2) comforts, and (3) coping. Each theme consisted of several subthemes as detailed below (see Figure 1).

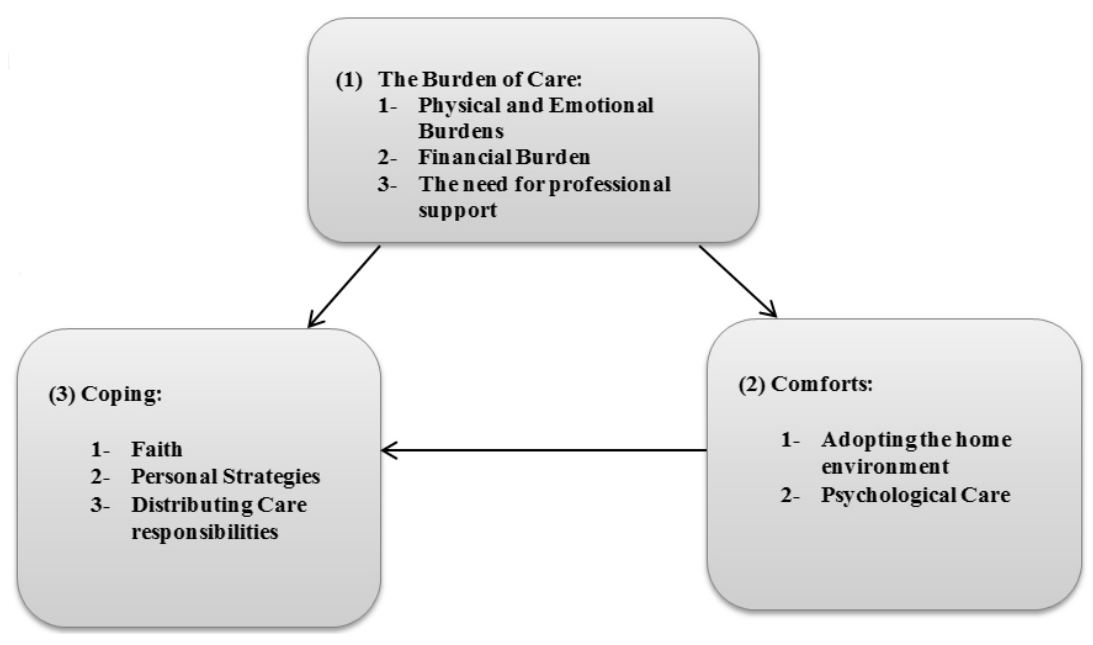

Figure 1. Themes and sub-themes 


\subsection{The burden of care}

All the caregivers experienced different challenges in giving care to their ill relative. The carers described and experienced many of these challenges as burdens that were of a physical, emotional, and financial nature. All of which were compounded by a lack of professional support.

\subsubsection{Physical and emotional burdens}

Caring for sick relatives at home involved caregivers helping their ill family member to carry out activities of daily living; this included bathing, changing, feeding, dispensing medications and attending hospital for appointments. When family members were bedridden, or mentally impaired the caregivers faced additional challenges of care:

Participant 5: "We carried him with sheet to the bathtub, we could not carry him with the wheel chair, we kept him in the bathtub and he cried from pain, we gave him bath with hot water, cleaned and washed him, and again he made dirt second time, then again we carried him with sheet covered." (Brother of a patient with bladder cancer)

While caregivers were deeply concerned for their ill family members, nonetheless, most of them experienced extreme fatigue, with many of them developing symptoms such as physical pain, insomnia, forgetfulness, headache, giddiness, reduced appetite and weight loss:

Participant 2: "I got very severe back pain and legs pain. I do not eat. I do not take breakfast, lunch, dinner, I get always giddiness. I eat only light food. I do not have appetite and I cannot eat. Actually, I do not have time to eat no time for myself, I lost weight." (Spouse of a patient with brain tumor)

It seems that caregivers were strained in their caring role because of the caring responsibilities. Most of them had no time to look after themselves. Few had other family members or friends to enable them to take time out from caring. Thus, many caregivers became sick themselves and those who already had health problems deteriorated further. Participant one was an extreme case of a family member playing two roles. She herself was diagnosed with advanced breast cancer, while at the same time she was the primary caregiver for her sister who also had a diagnosis of advanced breast cancer. She attributed her relapse due to constant nervousness and worry about her sister. It was evident that caring was emotionally draining for many of the carers:

Participant 1: "I cry a lot. I don't eat. I feel she is sick and I am sick with her. I get nervous, very nervous. Nervousness kills me. I get nervous because I feel she is suffering and in pain. I feel nervous; nobody talks with me as everybody knows that I am nervous because I am worried. I don't know what to do to her; I want to do everything for her." (Sister of Published by Sciedu Press a patient with breast \& ovarian cancer)

It seemed that many of the caregivers were emotionally distressed as a result of not knowing what to do to help the patients. In addition to the burdens of physical and emotional care, frequently a lack of financial resources added to their concerns.

\subsubsection{Financial burden}

Most caregivers were required to arrange resources to ease caring at home and help patients recover. In all cases medical care required additional monies. In some cases the hospital met some of the costs but frequently additional costs were met by donations from other family members and friends:

Participant 3: "The cylinder \& oxygen we should give a deposit of $75 \mathrm{BD}$. They said first $75 \mathrm{BD}$ and will give you a cylinder to take home. Since the Government is providing the Gas free, the cylinder has to be given free, no need for a deposit. My father's oxygen needs to be monitored so we bought a device that cost us 100 BD to check my father's oxygen, since the hospital has this device why do not they provide temporary for the patient?" (Daughter of a patient with lung cancer)

In general, caregivers did not face problems in arranging resources; frequently relatives and friends donated money even for extended medical care outside the country:

Participant 7: "When we took him Jordan the cost was high but thank God the relatives, everyone donated money because the cost was around 6,000 BD for treatment so thank God the relatives helped us, and good people." (Father of a patient with brain tumor)

\subsubsection{The need for professional support}

While relatives and friends helped in various ways, the participants expressed the need for professional support and advice, particularly for nurses to visit the home daily to assist them with the care and to provide information:

Participant 3: "It is very important that nurses visit home, at least the hospital sends a nurse. My father has few days left and he wants to live that at home so at least they should send nurses home for example three times to check him psychologically he will feel comfortable." (Daughter of a patient with lung cancer)

Participant (3) arranged a private nurse to help the family at night, but the other participants could not afford it. All of the caregivers managed all aspects of care on their own without opportunities for respite, hence it was reasonable for them to expect some professional assistance and expertise as a support with their caregiving role.

Several caregivers described that it was not possible for them 
to meet their doctors and when doctors were available they did not give needed information which made them anxious. Hence, few participants established personal relationship with the doctors and therefore received better assistance:

Participant 6: "It was a big problem for me, that the Dr could not answer because the Dr was changed and the new one was not available, it was difficult to see him and when you come for him he says he have million patients. No one solved this problem for me if she develops a breathing problem how could I solve it? There was no answer and I used to live in anxiety because of this problem only how can I face it at home?" (Son of a patient with breast cancer)

Participant 2: "When I complained about the incontinence they did not offer to arrange underpad or urinal. From my experience I requested underpad and bed. I requested also wheel chair but they told me $150 \mathrm{BD}$ so I bought it from outside. The doctor did not tell me about the bed although I told him how would I raise his bed for feeding at home? But he did not tell me about the bed. I was the one who requested the bed. They did not even tell me from where to get, I came and asked them. Also they did not teach me about feeding the patient." (Spouse of a patient with brain tumor)

The above data segments show that caregivers needed information about symptoms that may appear at home and how to manage those; unfortunately in the above cases, this information was not given. Participant 6 appreciated the palliative care clinic hotline service that he used to utilize to help him resolve some of the challenges he experienced in caring for his Mother; however, this service in Bahrain had recently been cancelled because of internal changes. An additional constraint for home caregivers was the lack of preparation prior to the discharge of their relative to the home. Some, however, had acquired care knowledge from previous experiences of caring while others depended on relatives and friends with nursing knowledge and some with professional nursing experience.

Participant 8: "His son is working as a trained practical nurse in an elderly house, he asked the Dr. and he told him use ensure food supplement for him it is very good, so we bought ensure and I feel he became better." (Daughter of a patient with non Hodgkin's lymphoma \& thyroid cancer)

\subsection{Comforts}

In spite of all the burdens of care, relatives strived to maintain all kinds of comfort for their ill relatives. Adopting the home environment and providing psychological care was central to ensuring comfort for the ill person.

\subsubsection{Adopting the home environment}

Most caregivers arranged the home in a way that did not stress the patients. Caregivers built new rooms, and redecorated houses. In addition, they maintained a serene atmosphere by avoiding quarrels and not sharing contentious home matters with the patients. It seems that caregivers tried their best to sustain a comfortable home atmosphere to facilitate patients' recovery.

Participant 6: "After her sickness, she could not go upstairs, and if she could it would make her tired, so we built for her in the home garden, a room in the ground, its door is to the hall, bathroom, everything is down, no need for her to go upstairs." (Son of a patient with breast cancer)

\subsubsection{Psychological care}

All caregivers appear to understand the crucial role good psychological well-being played in healing cancer patients:

Participant 3: "Once my father told me I feel upset. I do not know what's wrong with me because I'm not walking, I cannot walk, I told him who said you cannot walk? you can walk I will show you now that you can walk so I called my brothers. I told them my father is upset let's help him walk. We carried him and made him walk with his stick; he likes his stick when he holds it he feels he can walk. I let him to walk and the oxygen tube reached the house door. I asked my brother to bring the cylinder to the door, then I saw my father became tired so I brought the wheel chair and kept my father on the wheel chair and my brother dragged the cylinder outside till the road. We kept my father on the wheel chair and we kept the door open and I told my father look straight in front of you. I asked the small children to play in front of him so he could hear their voices, it was sunset time. I told my father breath the God air. But we could not take him faraway because the cylinder is heavy. I felt my father became fresh, he felt he can walk." (Daughter of a patient with lung cancer)

The above data segment illustrated how this caregiver and family worked together to give psychological comfort and care to the ill person. Caregivers tried to take patients outside the home even when they were bedridden. Others tried to be present for the patients all the time.

Participant 6: "I must make myself free for some time only for her. Morning I take breakfast with her; I talk and laugh with her. At noon I must spend one hour, at night I must keep one to half an hour to set with her. I must let her feel that I am present, what has happened, anything wrong, I make fun, go with her out for shopping, I take her Adhari park, we walk like that, we go everywhere." (Son of a patient with breast cancer) 
Additionally, caregivers used laughter as a way to heal patients. Some caregivers played and made fun with the patients and others appeared to use laughter to conceal their stress so patients would not notice their burden. According to them this was to avoid causing stress to the loved one.

Participant 1: "I make myself like a clown; I want her only to laugh. When she gets up from sleep she finds me changing my face in a funny way, wearing makeup in a funny way, I wear a funny very long dress, only I want her to laugh. I know when she laughs she becomes a little better." (Sister of a patient with breast $\&$ ovarian cancer)

It appears that caregivers understood the significance of psychological well-being for recovery and made every effort to maintain this sense of well-being for the ill person even if meant they had to suffer in silence:

Participant 8: "At the beginning, I always used to feel upset and bored, when he sees me he says I make you tired, I better die, you do not deserve this, carrying and putting me dawn. So I thought if we do this and he sees that he would be more sick." (Daughter of a patient with non Hodgkin's lymphoma $\&$ thyroid cancer)

\subsection{Coping}

Caregivers devised coping strategies such as, practicing their faith, developing their own personal strategies like regular exercise, and distributing the care responsibilities to other family members to help them in sustaining care for their relative.

\subsubsection{Faith}

A believe in God was the primary mode of coping practiced by all the caregivers in this study. Faith appears to help them realize what they were going through is a test from God. Some caregivers discovered first hand that Quran and prayer caused healing, as a result their faith strengthened and they could continue the caring experience:

Participant 3: "My faith has strengthened a lot. When I read Qur'an on my father and he becomes comfortable, I see for myself that God's words really give rest not the medicine, injection, or oxygen. I give him the prayer necklace and ask him to pray and I tell him as much as you pray you'll feel psychologically comfortable so he prays." (Daughter of a patient with lung cancer)

Participant 4: "Reading Quran and prayer, practicing obedience to god and thank God. We are Muslims and everything is in God hands: 'be and it shall be', thank God. God gave us patience." (Sister of a patient with breast cancer)

Published by Sciedu Press

\subsubsection{Personal strategies}

Participants who had supportive family coped by performing relaxation activities, exercising acceptance, patience and hope:

Participant 4: "I tolerated and maintained my patience. Why a one cannot have hope?" (Sister of a patient with breast cancer)

Some participants did not have family support during the caregiving experience; hence, they could not cope, the following excerpt is from a spouse of an advanced brain tumor patient:

Participant 2: "At night I release my entire held burden. Alone, I cry, talk alone, I became hopeless, alone in my room upstairs, he'll be downstairs with his mother. It does not help to cry a lot but I feel relieved a little." (Spouse of a patient with brain tumor)

Participant 2 did not have support from her family during caring so it seems she could not cope as she said: "I became hopeless", thus she appeared to try releasing her hidden burden through crying. The use of this phrase: "held burden" may reflect that she does not share her burden with others and "alone" possibly shows lack of support as was used in the previous extract under the "physical and emotional burdens" subtheme.

As a result of the caring experience all participants felt the caring role made them stronger. The data segments illuminate that caregivers experienced self-change as a result of the caring experience. They developed personal skills such as, strength, patience, kindness, love and confrontation and they helped in raising children:

Participant 1: "I became more kind, more loving. I became very strong, more confrontational, I don't feel shy. Whatever I need I do the impossible to get it, nothing stops in my way. I don't leave. I became very strong, too strong. I became strong from the sickness." (Sister of a patient with breast \& ovarian cancer)

\subsubsection{Distributing care responsibilities}

Usually caregivers coped with caring by distributing the care responsibilities among family members which helped the caregivers to cope with caring:

Participant 8: "We are four. I handle his appointments, his medicines throughout the day, if he needs anything I buy for him. Arranging his admission to the hospital, I bring him with the ambulance. His son and my cousin both give him bath daily, treat him. My mother role is 24 hours if he needs to pass urine, he calls her so she put urinal, she feeds him. When he passes stool my mother changes him." (Daughter of 
a patient with non Hodgkin's lymphoma \& thyroid cancer)

This strategy seemed to be successful in reducing the burden of the primary caregivers. In addition, sometimes relatives were unsupportive which caused tension to the caregivers and did not help them coping and sometimes it led to conflict:

Participant 2: "If I buy anything his brothers create problem for me. They are the administration. I cannot do anything on my own. I went to buy a commode chair because the toilet we have is Arabic style, imagine how would I carry him? They did not agree that I buy the chair." (Spouse of a patient with brain tumor)

Participant 5: "I fought with my brother, I told: 'brother you have been waiting for me until I come from city.' He said: 'I went 7 am his door was closed. I got up 8 am no one was available for me.' 'You should have brought your children, you have children.' He told me: 'You want to get rid of your brother, you do not want him', here I got little nervous." (Brother of a patient with bladder cancer)

The above data illustrates how some relatives could not manage caring for the ill persons and suggests that they did not receive support from other family members. The metaphor "administration" used by participant 2 to describe her husband's brothers may point to her struggle to care while simultaneously under male control, thus she felt unsupported and alone in the caring role. Participant 5 did not appear to have knowledge about how to care for his relative thus making him defensive with another family member.

\section{Discussion}

This study explored the phenomenon of caring for terminal cancer patients at home by their family caregivers. It illuminated the difficulties encountered giving care at home and of the requirements necessary to better manage care at home. The findings centered round three main themes: the burden of care, comforts and coping.

All the family caregivers felt burdened by giving home care to their sick relatives in various dimensions; physical, emotional, and financial. Carers were not prepared nor supported by health professionals before or during home care. In several systematic reviews, the burden of care is the most commonly reported experience for caregivers giving home care at EOL. ${ }^{[6,7,9-13,15,17-19]}$

The majority of participants administered physical care to ill relatives at home in the form of bathing, changing, feeding, and giving medications usually without pre training or ongoing support from health services. Similarly, Totman et al. ${ }^{[33]}$ reported care of terminal cancer patients at home involves physical care such as lifting, showering, feeding, washing, bowel care, positioning and turning the patients. All tasks that have to be carried out by caregivers who have usually limited knowledge and preparation to perform this role successfully. However, the health services in the reviewed studies support palliative patients and their families with home nursing care and hospice services, ${ }^{[18]}$ while these services are not available for the caregivers in Bahrain. As a consequence, most carers in this study developed fatigue and reduced appetite which ultimately resulted in a deterioration of their overall health.

All caregivers in this study experienced a myriad of emotional suffering as they moved through the journey of caring. They had emotional reaction and shock at time of diagnosis, or subsequently when relatives' health deteriorated. Some caregivers experienced severe emotional suffering because they had no one to support them during caring. Some like participant 2 internalized her stress for herself because she felt she had no one to talk to and that no one cared about her. Thus, she cried, talked to herself and felt hopeless. When there was no one available to assist carers, they became nervous and could not cope with caring. The majority of family caregivers shared the pain of their ill relatives; they felt sad, helpless and pitied the ill person as they watched them suffer. They felt intense emotions of nervousness, worry, anxiety and fear when they could not help patients or reduce their suffering from pain or other advanced symptoms.

This finding is similar to findings in the literature concerning the emotionality surrounding diagnosis, ${ }^{[15]}$ the worsening of a person's condition and subsequent suffering. ${ }^{[33]}$ A finding that concurs with Doumit et al.'s ${ }^{[20]}$ Arabic study which addressed the lived experience of Lebanese family caregivers of cancer patients, which showed that carers lived in a state of emergency filled with fears and uncertainty of what may occur to the ill person at any time. Similarly to the caregivers in this study, Lebanese caregivers appeared to share the pain of their loved ones. On the other hand, some carers chose to hide their stress to avoid causing negative reaction to their loved ones. In a similar vein, Stajduhar et al. ${ }^{[32]}$ showed that relatives submerged their feelings by will power and self-control.

While the caregivers in this study had to manage financially on their own because of lack of sufficient financial support from health services, nonetheless all caregivers managed to arrange the money to buy resources by receiving donations from other family members and friends. Similar to Van Houtven et al's. ${ }^{[34]}$ findings who reported considerable financial burden of 1,629 caregivers of lung and colorectal cancer patients, the caregivers in this study experienced financial distress and hardship. Availability or access to a 
hardship fund could perhaps alleviate some of the financial pressure for caregivers. A finding that also concurred with that of Woźniak \& Iżycki ${ }^{[35]}$ who reported that home palliative caregivers develop economic difficulty because of their caregiving responsibility.

The majority of participants emphasized the need for nurses to visit the home on a daily basis to assist them with caring. Some carers expressed that they had received no education about home caring. Rather they learnt by trial and error. All of which added to their worries and uncertainties around caring. A finding that relates to caregivers lack of preparedness and feelings of fear, anxiety, stress, inadequacy and uncertainty about their ability of providing home care. ${ }^{[20,35-39]}$ Furthermore, the literature affirmed that there was no discussion about what to expect in palliative home care and carers felt health professionals were hesitant to discuss difficult issues like managing palliative care at home and end of life care. ${ }^{[40]}$ Thus, they learned caregiving skills by trial and error. ${ }^{[18,41]}$ Some caregivers in this study described that they experienced difficulties trying to get in touch with their doctors to clarify their doubts. While they understood that the doctor might be busy with many patients, however, the majority expressed the need to increase the number of oncologists in the health services. On the other hand, carers received good support from doctors when they had developed a personal relationship with them, a finding also reported by Docherty et al. ${ }^{[19]}$ who systematically reviewed the knowledge and information needs of caregivers during palliative care. A palliative care clinic hotline service would somewhat assist carers. This was previously available in Bahrain and carers attested to its value in supporting their caring experience. Likewise, caregivers believed that supporting them would considerably reduce their feelings of negativity while caring for a loved one at home. ${ }^{[25]}$ In a systematic review about caregivers needs in providing home based end of life care for cancer patients, Bee et al. ${ }^{[18]}$ identified that caregivers emphasized the significance of 24 hours hospice nurse in assisting them with technical problems, and decision making that helped to reduce their anxiety during home caregiving. Thus, the evidence suggests that caregivers and patients benefit from home nursing care services focused on their needs. ${ }^{[42]}$ Unlike the caregivers from the reviewed studies, home nursing care and hospice services are not currently available for the caregivers in Bahrain.

Although family members in this study were burdened in their journey of caring for their sick relatives, nevertheless they strived to maintain all kinds of comforts around patients environment. A finding that is congruent with Totman et al. ${ }^{[33]}$ who documented that caregivers' main focus was on maintaining comfort and quality of life for their patients.
This was achieved by protecting the family member from thoughts of death by hiding the reality of prognosis and providing comfort through distraction.

Most caregivers in this study affirmed that they modified the home environment to avoid stressing the patient and ease caring. This was usually achieved by changing the location where patients sleep. For example, when patients' rooms were upstairs, caregivers usually built new rooms with bathrooms downstairs and patients' things were kept within reach. Often homes were turned like a hospital setting. Relatives redecorated homes to ensure patients safety. Safety handles were placed in the halls and bathrooms. Few caregivers bought calling bells for the patients to call them when help is needed. Similar alterations of the home environment were also reported by Milligan et al. ${ }^{[43]}$ who examined the experiences of relatives after home death. In addition, Collier et al. ${ }^{[44]}$ examined the meaning of home at the end of life, one of the emergent themes was "home becomes hospital", in which participants described home as taking hospital like qualities.

All caregivers relied on psychological care to comfort the patients. This was achieved by maintaining a relaxed atmosphere around the patients. In addition, a few caregivers requested other relatives to visit patients daily so they would not feel socially neglected or isolated. Other caregivers supported patients by being physically present all the time. This is similar to the findings by Northfield and Nebauer's ${ }^{[45]}$ study of caregivers journey which noted the caregivers desire to be present as proof that they fulfilled their role. In addition, caregivers in this study tried to take patients out as much as possible even when the patients were bedridden. In some cases family members arranged private medical support to provide reassurance and psychological support for the ill person and family. This finding supports the significance of providing psychological support for patients which is also well documented in literature. ${ }^{[42]}$ Furthermore, relatives used laughter to comfort patients. It seems that caregivers instinctively knew that laughter is a healing modality. In the same way, Northfield and Nebauer ${ }^{[45]}$ showed that caregivers employed laughter to strengthen their relationship with the patients.

Caregivers in this study used three mechanisms to cope, faith, personal strategies and distributing the care responsibilities. Similar findings have been documented in literature, Stajduhar et al. ${ }^{[32]}$ found factors which assisted caregivers coping, were the caregiver's having a positive approach to life and supportive networks of family and friends who provided practical help and listened to the caregiver when needed. Faith is the first coping method reported by all the caregivers 
in this study who were Muslims, thus, they practiced Islamic religious activities such as, praying, reading Qur'an, visiting holy places and drinking holy water. Performing religiour rites at the end-of-life is seen as a source of comfort for both family members and is sometimes a way of signaling that death may be near, as evidenced by O'Neill et al. ${ }^{[46]}$ The caregivers practiced religious activities on daily basis and encouraged patients to do so as well. Some caregivers witnessed healing as a result of practicing religious activities believing that God is the source of miracles. Likewise, the literature showed that faith is an important mechanism for coping to deal with stress, fear, and, uncertainty, it is the bond that gets family members together even during tension. ${ }^{[20,33,36]}$ Engaging in religious acts is believed to please God and facilitate Muslims entrance to heaven. ${ }^{[47]}$ Since all caregivers in this study were Muslims they helped their sick relatives as a way of showing obedience to God which may explain their commitment to caregiving. Similarly, Lebanese caregivers relied on God to cope with the burden of care, and like the caregivers in this study they considered God as the source of miracles. ${ }^{[20]}$

Many of the caregivers in this study experienced feelings of social isolation and stress, findings that concur with those of Funk et al. ${ }^{[11]}$ They attempted to minimize these feelings by engaging in regular exercise and other social activities. Despite these negative experiences many of the caregivers affirmed that they felt the caring experience made them stronger, more loving, kind and patient. Others found that they became more confrontational as they had to fight the healthcare system for patients' needs. Moreover, caregivers and patients relationship became stronger. Turner et al. ${ }^{[48]}$ also revealed that older caregivers of spouses dying at home appreciated the opportunity to give homecare and described their commitment to fulfill the wish of their spouses dying at home. Moreover, they were surprised about their resilience in coping with caregiving that was challenging. In spite of that, they generally reported a positive view of the whole experience. In line with that, Totman et al. ${ }^{[33]}$ also found family caregivers viewed homecare of a family member with terminal cancer as giving something back to the ill family member and they enjoyed the time spent with the dying relative. Furthermore, they had the opportunity to renew and deepen their relationship with their dying relative.

Caregivers in this study managed care by distributing the care responsibilities among family members. Participant 3 described how having other family members around helped her, and used the metaphor of an "army" to describe the power of support she felt by their presence. Similarly, van Eechoud et al. ${ }^{[36]}$ in a study that involved Muslim family caregivers of Arab and Turkish origin documented that care- giving tasks were shared between family members.

On the other hand, another participant found having family members around intrusive and she experienced this as a sort of checking up on her. She used the word "administration" to convey this feeling. It seems she felt the dominance of the males members of her husband's family as controlling because they did not allow her to arrange resources to assist her with the caring. She also described feeling "alone" during caring as no one bothered to ask about her. This finding is similar to Stenberg et al. ${ }^{[49]}$ and Rokach et al. ${ }^{[50]}$ who both documented caregivers without support from friends and family developed considerable loneliness.

Another participant expressed how family conflicts arose as a result of the caring responsibilities. Likewise, Fergus and Gray ${ }^{[51]}$ reported family conflicts during the caregiving experience. Funk et al. ${ }^{[11]}$ in a review of qualitative research about home based family caregiving at the EOL reported that formal and informal support facilitates caregivers coping. Generally the caregivers in this study who had good support had positive coping experiences, while the caregivers without adequate support had negative coping experiences.

Interestingly, all the caregivers with the exception of one were able to maintain the role of primary caregiver until the end, Woodman et al. ${ }^{[52]}$ explained that family caregivers carry out the role of caregiving through a sense of obligation and duty, which may elucidate the reason the caregivers in this study were successful at the role and that they coped despite all the challenges of caregiving.

\section{Conclusions}

The study was about the experience and needs of family caregivers providing home care for terminal cancer patients. The research design was a qualitative Heideggerian phenomenological approach. The findings emerged under three themes: (1) the burden of care, (2) comforts, and (3) coping. The burdens of care were associated with physical, emotional and financial burdens, adding to that lack of professional support was reported. This caused a multitude of emotions that caregivers suffered throughout the experience of caring. In spite of all the burdens, the caregivers strived to maintain comfort at home even if they had to hide their stress from patients. The home environment was adjusted to promote comfort for the ill persons. In addition, resources were arranged with or without hospital assistance. Throughout the process, caregivers experienced financial strain which was somewhat alleviated by the support of relatives and friends. The carers provided psychological support by ensuring to take patients out even when they were bedridden, and laughter was utilized to comfort and process stress. Carers coped through faith in 
God which dominated the whole experience and provided an outlet for hope and healing. Further, carers utilized personal strategies to cope through maintaining strength and patience. Family togetherness helped the caregivers to distribute the caring responsibilities.

The family caregivers lived experiences illuminated a number of different needs. There is a need to initiate home nursing care and hospice services to assist the burdened caregivers. Until those services are found, unprepared caregivers will continue practicing palliative care at home using trial and error. The palliative care clinic hotline service needs to be re-activated. A policy for needs assessment should be implemented to assess patients and family needs on admission. Moreover, training sessions on basic nursing care should be designed and delivered to caregivers before discharging patients. The family members voiced a need to increase the number of oncologists. Furthermore, booklets could be made available to relatives about the services and resources the hospital provide. The institution should survey patients and family satisfaction with health services on annual basis. Finally, most of the nurses involved in oncology and palliative care are not specialized. Thus, it is recommended that Nursing colleges establish diploma programs in oncol- ogy and palliative care to increase the quality of oncology services in the Kingdom of Bahrain.

\subsection{Future research}

A mixed method study is recommended for further research. Furthermore, the findings could guide the development of needs assessment tool that is sensitive to the culture of Bahrain. Also, the needs of healthcare providers to provide quality care should be investigated.

\subsection{Limitations}

The nature of the research being qualitative with a small sample size means the findings could not be generalized to the whole population. In addition, the researcher had limited time as the study was in part fulfilment for an MSc degree in nursing.

\section{ACKNOWLedgements}

The work was carried out as part fulfillment for an MSc in Nursing \& Midwifery in the School of Nursing \& Midwifery, Royal College of Surgeons in Ireland, Bahrain.

\section{CONFlicts of InTEREST Disclosure}

The authors declare they have no conflicts of interest.

\section{REFERENCES}

[1] Al Awadhi MA, Al Fateh NM, Hassan FA, et al. Cancer Incidence and Mortality in the Kingdom of Bahrain Statistics and Trends. Bahrain Medical Bulletin. 2016 Mar; 38(1): 30-4. Available from: http: // www.bahrainmedicalbulletin.com/issue_march2016.htm

[2] Al Madouj AN, Eldali A, Al Zahrani AS. Ten-Year Cancer Incidence Among Nationals of The GCC States, 1998- 2007. Gulf Center for Cancer Control and Prevention. 2013 Jul; 88-98. Available from: https://www.moh.gov.bh/Content/Files/Publicati ons /GCC $\% 20$ Cancer $\% 20$ Incidence $\% 202011$.pdf

[3] Health Statistics of 2015. Ministry of Health Statistics. Health Information Directorate. 2017 [cited 2017 Aug 1]. Available from: https://www.moh.gov.bh/Ministry/Statistics?lang=en

[4] The Minister Office. Budget Preparation of 2009-2010 Priorities as Identified By H.E. the Minister. Ministry of Health; 2009.

[5] Davies B, Steele R. Supporting Families in Palliative Care. In: Ferrell BR, Coyle N, editors. Oxford Textbook of Palliative Nursing. 3rd ed. New York: Oxford University Press; 2010. 613-627 p. https://doi.org/10.1093/med/9780195391343.003.0032

[6] Stajduhar KI. Burdens of Family Caregiving at the End of Life. Clinical \& Investigative Medicine. 2013 Jan; 36(3): 121.

[7] Martín JMCAD, Olano-Lizarraga M, Saracíbar-Razquin M. The experience of family caregivers caring for a terminal patient at home: A research review. International Journal of Nursing Studies. 2016; 64: $1-12$.

[8] Yoo JS, Lee JH, Chang SJ. Family Experiences in End-of-Life Care: A Literature Review. Asian Nursing Research. 2009; 2(4): 223-34. https://doi.org/10.1016/S1976-1317(09)60004-9
[9] Grande G, Stajduhar K, Aoun S, et al. Supporting lay carers in end of life care: current gaps and future priorities. Palliative Medicine. 2009; 23(4): 339-44. PMid: 19304804. https://doi.org/10.1 $177 / 0269216309104875$

[10] Hudson P, Payne S. Family Caregivers and Palliative Care: Current Status and Agenda for the Future. Journal of Palliative Medicine. 2011; 14(7): 864-9. PMid: 21599532. https://doi.org/10.108 9/jpm. 2010.0413

[11] Funk L, Stajduhar K, Toye C, et al. Part 2: Home-based family caregiving at the end of life: a comprehensive review of published qualitative research (1998-2008). Palliative Medicine. 2010; 24(6): 594-607. PMid: 20576673. https://doi .org/10.1177/026921 6310371411

[12] Hudson PL, Trauer T, Graham S, et al. A systematic review of instruments related to family caregivers of palliative care patients. Palliative Medicine. 2010 Jun; 24(7): 656-68. PMid: 20605852. https://doi.org/10.1177/0269216310373167

[13] Stajduhar K, Funk L, Toye C, et al. Part 1: Home-based family caregiving at the end of life: a comprehensive review of published quantitative research (1998-2008). Palliative Medicine. 2010; 24(6): 573-93. PMid: 20562171. https://doi.org/10.1177/026921 6310371412

[14] Girgis A, Lambert S, Johnson C, et al. Physical, Psychosocial, Relationship, and Economic Burden of Caring for People With Cancer: A Review. Journal of Oncology Practice. 2013; 9(4): 197-202. PMid: 23942921. https://doi.org/10.1200/JOP. 2012.000690

[15] Leseure P, Chongkham-Ang S. The Experience of Caregivers Living with Cancer Patients: A Systematic Review and Meta-Synthesis. Jour- 
nal of Personalized Medicine. 2015; 5(4): 406-39. PMid: 26610573. https://doi.org/10.3390/jpm5040406

[16] Given BA, Given CW, Sherwood P. The Challenge of Quality Cancer Care for Family Caregivers. Seminars in Oncology Nursing. 2012; 28(4): 205-12. PMid: 23107177. https ://doi.org/10.1016/j . soncn.2012.09.002

[17] Hughes PM, Ingleton MC, Noble B, et al. Providing cancer and palliative care in rural areas: a review of patient and caregiver needs. $\mathrm{J}$ Palliat Care. 2004; 20: 44-49. PMid: 15132076.

[18] Bee PE, Barnes P, Luker KA. A systematic review of informal caregivers' needs in providing home-based end-of-life care to people with cancer. Journal of Clinical Nursing. 2009; 18(10): 1379-93. https://doi.org/10.1111/j.1365-2702.2008.02405.x

[19] Docherty A, Owens A, Asadi-Lari M, et al. Knowledge and information needs of informal caregivers in palliative care: A qualitative systematic review. Palliat. Med. 2008; 22: 153-171. https: //doi.org/10.1177/0269216307085343

[20] Doumit MAA, Huijer HAS, Kelley JH, et al. The Lived Experience of Lebanese Family Caregivers of Cancer Patients. Cancer Nursing. 2008; 31(4). PMid: 18600109. https://doi.org/10.1097/01.N CC. $0000305751.28120 . f 4$

[21] Funk LM, Allan DE, Stajduhar KI. Palliative family caregivers accounts of health care experiences: The importance of "security". Palliative and Supportive Care. 2009; 7(04): 435. https: //doi.org/10.1017/S1478951509990447

[22] Smith JA, Flowers P, Larkin M. Interpretative Phenomenological Analysis. Theory, Method and Research. 1st ed. London: Sage Publications Ltd; 2009.

[23] Schneider Z, Whiehead D, Elliott D, et al. Nursing and Midwifery Research: Methods and Appraisal for Evidence-Based Practice. 3rd ed. Sydney: Mosby-Elsevier; 2007.

[24] Eatough V, Smith J. Interpretive Phenomenological Analysis. In: Willing C, Stainton-Rogers W, editors. The Sage Handbook of Qualitative Research in Psychology. London: Sage Publications Ltd; 2008. https://doi.org/10.4135/9781848607927.n11

[25] Kukeya CB. Home Caring For Spouses with Terminal Cancer in the Last Stages of Their Illness: A Phenomenological Study of MiddleAged Caregivers. ProQuest Dissertations and Theses; ProQuest Nursing \& Allied Health Source. University of the Incarnate Word; 2006 May. $134 \mathrm{p}$.

[26] Nieswiadomy R M. Foundations of Nursing Research. 4th ed. New Jersey: Prentice Hall; 2002.

[27] Morasso G, Costantini M, Di Leo S, et al. End-of-Life Care In Italy: Personal Experience Of Family Caregivers. A Content Analysis of Open Questions from the Italian Survey of the Dying Of Cancer (ISDOC). Psycho-Oncology. 2008; 17: 1073-1080. PMid: 18317991. https://doi.org/10.1002/pon.1332

[28] Tuffour I. A Critical Overview of Interpretative Phenomenological Analysis: A Contemporary Qualitative Research Approach. Journal of Healthcare Communications. 2017; 02(04): 52.

[29] Pringle J, Hendry C, Mclafferty E. Phenomenological Approaches: Challenges and Choices. Nurse Researcher. 2011; 18(2): 7-18. https://doi.org/10.7748/nr2011.01.18.2.7.c8280

[30] McBrien B. Evidence-Based Care: Enhancing the Rigour of a Qualitative Study. British Journal of Nursing (BJN). 2008 Nov; 17(20): 1286-1289. https://doi.org/10.12968/bjon.2008.17.20.3 1645

[31] Tong A, Sainsbury P, Craig J. Consolidated criteria for reporting qualitative research (COREQ): a 32-item checklist for interviews and focus groups. International Journal for Quality in Health Care. 2007; 19(6): 349-57. PMid: 17872937. https://doi.org/10.1093/in tqhc/mzm042
[32] Stajduhar KI, Martin WL, Barwich D, et al. Factors Influencing Family Caregivers Ability to Cope With Providing End-of-Life Cancer Care at Home. Cancer Nursing. 2008; 31(1): 77-85.

[33] Totman J, Pistrang N, Smith S, et al. 'You only have one chance to get it right': A qualitative study of relatives' experiences of caring at home for a family member with terminal cancer. Palliative Medicine. 2015; 29(6): 496-507.

[34] Van Houtven CH, Ramsey SD, Hornbrook MC, et al. Economic Burden For Informal Caregivers Of Lung And Colorectal Cancer Patients. Oncologist. 2010; 15(8): 883-893. PMid: 20667966. https://doi.org/10.1634/theoncologist.2010-0005

[35] Woźniak K, Iżycki D. Cancer: a family at risk. Menopausal Review. 2014; 4: 253-61.

[36] van Eechoud IJ, Grypdonck M, Leman J, et al. Caring for Family Members Older Than 50 Years of Turkish and Northwest African Descent. Cancer Nursing. 2015; 1.

[37] Cagle JG, Kovacs PJ. Informal Caregivers of Cancer Patients: Perceptions About Preparedness and Support During Hospice Care. Journal of Gerontological Social Work. 2011; 54(1): 92-115.

[38] Holm M, Henriksson A, Carlander I, et al. Preparing for family caregiving in specialized palliative home care: An ongoing process. Palliative and Supportive Care. 2014 Sep; 13(03): 767-75.

[39] Payne S, Turner M, Seamark D, et al. Managing end of life medications at home-accounts of bereaved family carers: a qualitative interview study: Table 1. BMJ Supportive \& Palliative Care. 2014; 5(2): 181-8.

[40] Hunstad I, Svindseth MF. Challenges in Home-Based Palliative Care in Norway: A Qualitative Study of Spouses' Experiences. International Journal of Palliative Nursing. 2011 Aug; 17(8): 398-404. https://doi.org/10.12968/ijpn.2011.17.8.398

[41] Kalnins I. Caring For the Terminally Ill: Experiences of Latvian Family Caregivers. International Nursing Review. 2006 June; 53(2): 129-135. https://doi.org/10.1111/j.1466-7657.2006.004 $78 . \mathrm{x}$

[42] Ferrell BR, Coyle N, editors. Oxford Textbook of Palliative Nursing. 3rd ed. New York: Oxford University Press; 2010. https: //doi.org/10.1093/med/9780195391343.001.0001

[43] Milligan C, Turner M, Blake S, et al. Unpacking the impact of older adults home death on family care-givers experiences of home. Health \& Place. 2016; 38: 103-11.

[44] Collier A, Phillips JL, Iedema R. The meaning of home at the end of life: A video-reflexive ethnography study. Palliative Medicine. 2015; 29(8): 695-702.

[45] Northfield S, Nebauer M. The Caregiving Journey For Family Members of Relatives with Cancer: how do they cope? Clinical Journal of Oncology Nursing. 2010 Oct; 14(5): 567-77.

[46] O'Neill SC, Yaqoob M, Faraj S, et al. Nurses' Care Practices at the End of Life in Intensive Care Units in Bahrain. Nursing Ethics. 2016 Feb 22. https://doi .org/10.1177/0969733016629771

[47] Bauer-Wu S, Barrett R, Yeager K. Spiritual Perspectives and Practices at the End-Of-Life: A Review of the Major World Religions and Application to Palliative Care. Indian Journal of Palliative Care. 2007; 13(2): 53-58

[48] Turner M, King C, Milligan C, et al. Caring for a dying spouse at the end of life: 'Its one of the things you volunteer for when you get married': a qualitative study of the oldest carers experiences. Age and Ageing. $2016 \mathrm{Jul}$; 45(3): 421-6. https ://doi .org/10.1093/ ageing/afw047

[49] Stenberg U, Ruland CM, Miaskowski C. Review of the literature on the effects of caring for a patient with cancer. Psycho-Oncology. 2010; 19: 1013-1025. 
[50] Rokach A, Matalon R, Safarov A, et al. The Loneliness Experience Of The Dying And Of Those Who Care For Them. Palliative \& Supportive Care. 2007 Jun; 5(2): 153-9. PMid: 17578066. https://doi.org/10.1017/S1478951507070228

[51] Fergus KD, Gray RE. Relationship vulnerabilities during breast cancer: patient and partner perspectives. Psycho-oncology. 2009 Dec; 18(12): 1311-22. Available from: http://onlinelibrary . wiley.com/doi/10.1002/pon.1555/abstract; jsessionid $=$ DC657385F36D6DAA5D7A9FEF 1 AB38502.f03t03

[52] Woodman C, Baillie J, Sivell S. The preferences and perspectives of family caregivers towards place of care for their relatives at the end-of-life. A systematic review and thematic synthesis of the qualitative evidence. BMJ Supportive \& Palliative Care. 2016 Dec 1; 6(4): 418-429. PMid: 25991565. https://doi.org/10.1136/bmjspc are-2014-000794 